\title{
Environmental Protection as Disasters' Risk Reduction Strategy in Rwanda: Knowledge, Attitudes and Practices of Community Members in Kamonyi District
}

\author{
Narcisse NTAWIGENERA ${ }^{1 *}$, Dr. Callixte YADUFASHIJE ${ }^{2}$ \\ ${ }^{I}$ Catholic University of Rwanda, Faculty of Public Health and Humana Nutrition, Department of Public Health. \\ Rwanda \\ ${ }^{2}$ INES-Ruhengeri-Institute of Applied Sciences
}

*Corresponding Author: Narcisse NTAWIGENERA, Catholic University of Rwanda, Faculty of Public Health and Humana Nutrition, Department of Public Health. Rwanda

\begin{abstract}
The objective of this research was to assess knowledge, attitudes and practices of community members towards environmental protection as disasters' risk reduction strategy. It has been conducted in 3 sectors of Kamonyi district located in Southern Province of Rwanda: Kayenzi, Gacurabwenge and Runda. 384 respondents participated in this research. Findings revealed that $76 \%$ of respondents are aware of environmental degradation problem. $62 \%$ confirmed that there is a direct relationship between environmental degradation and disasters. Regarding their attitudes, prevention of soil erosion is the most appreciated environmental protection technique as contributing on disasters' risk reduction. Soil erosion, climate change, over-cultivation and environmental impact of pesticides and fertilizers are key environmental issues associated with agricultural sector in Kamonyi district. Mining activities are "over controlled" in order to avoid their impact on the environment. However, disasters related to water pollution, deforestation and accidents are the main problems identified as associated to mining activities. According to findings of research, efforts are needed for improvement of knowledge of community members, in order to reduce their vulnerability to disasters. In addition, behavior change programs are much needed in this area, so that sustainable development goals may be achieved.
\end{abstract}

Keywords: Environment, Environmental protection, Environmental degradation, Hazard, Disaster, Knowledge, Attitudes and Practices.

\section{INTRODUCTION}

The world is facing an increasing frequency and intensity of disasters (natural and man-made) that has had devastating impacts. As reported by the secretariat of the International Strategy for Disaster Reduction (ISDR, 2015), the last ten years have seen 478,100 people killed, more than 2.5 billion people affected and about US\$ 690 billion in economic losses. Disasters triggered by hydrometeorological hazards amounted for 97 percent of the total people affected by disasters, and 60 percent of the total economic losses. Environmental changes, such as anthropogenic global warming, promise to create new challenges to the security and sustainability of communities around the world. (http://www.gdrc.org/uem/disasters/disenvi/intro.html).

Environmental degradation, settlement patterns, livelihood choices and human behavior are all factors contributing to disaster risks, which in turn results in harmfully effects on human development and environmental assets (ISDR, 2015). Over the last decade, the frequency and intensity of natural hazards induced disasters in Rwanda. Particularly, floods and droughts have significantly increased, raising the toll of human casualties as well as economic and environmental losses. Rwanda's disaster profile is dominated by heavy rains, floods, landslides, droughts, fire, earthquakes, diseases and epidemics that disrupt people's lives and livelihoods, destroy the infrastructure and interrupt economic activities and retard development (MIDMAR, 2012).

Environmental protection is recognized as having an important role in the field of Disaster Risk Reduction. The Rwanda national disaster management policy emphasizes preparedness of the Government, communities and other stakeholders for Disaster Management activities. It aims at the establishment and strengthening of Disaster Management institutions, partnerships while 
mainstreaming Gender, Human Rights and Climate Change into Disaster Management activities. The ultimate goal is to increase the resilience of vulnerable groups to disasters. The policy presents the institutional structures, roles, responsibilities, authorities and key processes required to achieve a coordinated, coherent and consistent management of disaster related issues.

Disaster Risk reduction is everyone's responsibility and involves many areas of activity. Increasing the capacity of communities to prevent, withstand and recover from a disaster plays a major role in reducing the severity of its impact. The United Nations International Strategy for Disaster Reduction (UN/ISDR) defines Risk as a function of Hazard, Vulnerability and Capacity. Coping Capacity is the manner in which people and organizations use existing resources to achieve various beneficial ends during unusual, abnormal and adverse conditions of a disaster event or process. Although the inherent links between disaster reduction and environmental management are recognized, little research and policy work has been undertaken on the subject. There is a clear need to reinforce the importance of environmental concerns in the entire disaster management cycle of prevention, preparedness, assessment, mitigation and response and to integrate environmental concerns into planning for relief, rehabilitation, reconstruction and development. This requires the enhancement of capacities to undertake short and medium-term activities in disaster management based on long-term environmental considerations. This research is aimed at evaluation of knowledge, attitudes and practices of local communities in Rwanda towards natural disasters and risk reduction strategies through environmental protection.

The commitment of Government of Rwanda towards environment management has been demonstrated through various initiatives. Policies, laws, international conventions and treaties, institutions and funds aimed at environmental protection are tangible proof of this commitment. On the other hand, preventing, mitigating, responding, recovering, securing, monitoring and timely acting positively in order to promote disaster awareness culture within a sector policy framework oriented to management of natural and man-made disasters risks are among the main preoccupations of Government of Rwanda. As well known, awareness at community level is necessary to achieve consensus and obtain commitment from local public authorities about disaster risk reduction policies. However, disaster management seems to be known as reactive and focuses on crisis management and the emergency assistance (relief) need only after a disastrous event has occurred at the community level. The relationship between environmental protection and disaster risk reduction seems to be not known by community members. In fact, their practices contributing to environmental degradation imply wondering their knowledge with regards to environmental protection as disasters risk reduction strategy. Deforestation, mining activities, farming techniques, non-use of renewable energy and practices related to building activities are among main practices contributing to environmental degradation and therefore to the increase of disasters risks in Rwanda in general, and particularly in Kamonyi district. However, there are policies, laws and programs aimed at limitation of the effects of these practices on the environment. The problem is to know why they are not respected accordingly. The inventory of these practices as well as attitudes related to environmental degradation can be an opportunity for decision-makers to reduce disasters risk, and enhance community resilience.

\section{MATERIALS AND METHODS}

\subsection{Study Design}

This study adopted quantitative and qualitative approaches to assess the knowledge, attitudes and practices of local communities towards environmental protection as disasters risks reduction strategy. Open and closed questions were used to assess knowledge, attitudes and practices of local communities towards environmental protection as disasters risks reduction strategy.

\subsection{Study Population}

According to (Grinnell et al., 1990), study population is the totality of the persons or objects with which a study is concerned. The study population was the population of Kamonyi district of Southern Province in Rwanda. Therefore, the total population of this study was 342,792 inhabitants (Kamonyi District, 2013).

\subsection{Sample Size and Sampling Procedure}

\subsubsection{Sample Size}

The sample size was calculated using Microsoft Raosoft for the population size of 342,792 inhabitants, with margin of error of 5\% and confidence level of $95 \%$. The recommended sample size has been 384 inhabitants. 


\subsubsection{Sampling Procedures}

The sampling selection techniques applied during this research was identified by using a randomly sampling method from the population of 3 sectors of Kamonyi district: Kayenzi, Gacurabwenge and Runda. During the data collection procedures, we chose respondents from various categories of persons, especially those contributing to environmental degradation and environmental protection.

\subsection{Data Collection Tools and Methods}

\subsubsection{Questionnaire}

A questionnaire is a set of questions designed to generate the data necessary for accomplishing the objectives of the research. The questionnaires were designed and then translate in Kinyarwanda to facilitate those respondents that could not understand English.

\subsubsection{Focus Group Discussions}

Participants were organized in a group of 6-8 people at each study site or sector. Each group was requested to present its views in an open environment. Focus group discussions were conducted in order to get a diversity of answers and experiences that are harmonized in this research.

\subsubsection{Interviews with Key Informants}

This was mainly targeting key informants such as local political leaders, land officers, community development officers, among others. Their views, observations, and experiences with regard to the research problem were sought. Face to face interviews were carried out with respondents who participated in the study as key informants.

\subsection{Data Processing and Analysis}

Data have been organized in a meaningful patterns for the purpose of presenting them in more comprehensive form. This phase involved analysis of raw data through tabulation and conducting statistical procedures on the collected data. Both qualitative and quantitative analysis have been used. Data from the questionnaires were processed using SPSS and EXCEL software. The results were compared to those that resulted from the analysis of interview data. From this comparison, conclusions were drawn.

\section{RESULTS AND DISCUSSION}

\subsection{Knowledge about the Need of Environmental Protection for Prevention of Disasters}

Findings of this research revealed that $76 \%$ of respondents are aware of environmental degradation problem. Only $7 \%$ of respondents have confirmed that environmental degradation is not happening, while $17 \%$ responded that they don't know. About the relationship between awareness on environmental degradation and occupation of respondents, results have demonstrated that the big number (81) of those who are not aware of environmental degradation problem are among farmers. However, Focus Group Discussions conducted with the group of farmers in Kayenzi sector as well as interview with local leaders revealed that the position of those who denied the environmental degradation problem was influenced by the belief in effectiveness of environmental protection strategies. "We have taken strong decisions for environmental protection: for those who are in agricultural sector, they are controlled. Nobody can cut down a tree anyhow. We are planting bamboos at Nyabarongo river. The population is taught to protect the soil: prevention of erosion, terracing, etc. You cannot find anywhere a polythene bag. Really, our environment is protected and it cannot be degraded". Said one local leader.

About the process through which community members learn about environmental protection and disaster management, most of them have mentioned radio (278), schools (234), trainings (178) and meetings (153) as main channels through which they acquire this knowledge. Human epidemics are the first category of disasters experienced in areas of respondents, as confirmed by $96 \%$ of them. It is followed by landslides (94\%), crops and animal epidemics (88\%), floods $(72 \%)$, earthquake $(71 \%)$, drought $(60 \%)$ and famine $(59 \%)$. 62\% of respondents have confirmed that there is a direct relationship between environmental degradation and disasters. $16 \%$ have denied the existence of relationship between environmental degradation and disasters, while $22 \%$ of respondents have not 
confirmed or denied this relationship. In fact, the argument of those denying the relationship between environmental degradation and disasters is related to the nature of disasters. They confirm that disasters are natural, and they cannot be prevented. "How can you explain me the relationship between cutting trees and raining? They prevented us to use polythene bags saying that there will no longer be a problem! For me, I do not accept all these!" This is a declaration of one farmer in Gacurabwenge sector. These findings are in line with findings by other researchers who argue that one of the greatest limitations to environmental protection is lack of environmental degradation information. However, it is important to quickly note that vast majority believe environmental degradation is happening as they did observe that there were changes in their local environment. As far as respondents are concerned, the concept of environmental degradation remains a technical subject. It's important to raise awareness on environmental protection. This also means that channels of information are somehow available at grassroots through which rural communities can get the information related to environmental protection.

\subsection{Attitudes towards Environmental Protection Strategies Aimed at Disasters' Risk Reduction}

Disasters are mainly social constructs: they are largely determined by how a society manages its environment, how prepared it is to face adversity and what resources are available for recovery. As pointed out by Moser and Satterthwaite (2008), the more assets people have, the less vulnerable they are and the greater the erosion of people's assets the greater their insecurity. Such assets also include the access to healthy ecosystems (Sudmeier-Rieux, K. and Ash, N., 2009).

Findings of this research revealed that the most appreciated technique as contributing on prevention of disasters is prevention of erosion. 240 out of 384 respondents strongly agree with its effectiveness. The effective waste management (222/384), farming techniques (215/384), as well as limitation of population growth (213/384) are other practices which are highly appreciated by respondents. The use of renewable energy sources and non use of artificial fertilizers are practices less appreciated by respondents. 63 and 44 participants have respectively mentioned that they strongly disagree with the contribution of these practices on disasters risks reduction. In the same line, 48 and 38 respondents disagree respectively with effectiveness of farming techniques and prevention of polythene bags use as disasters risks reduction strategies. During Focus groups discussions and interview with key informants, respondents have strongly acknowledged the contribution of farming techniques and prevention of erosion as effective strategies for prevention of earthquake. "If there were not terraces and canalizations, I can confirm that no soil could be up to now at this village. Previously, we used to cultivate and the soil were transported away. But now the solution has been found". This is a declaration of one respondent, in Kayenzi sector.

The population growth is considered as a factor contributing on the increase of disasters risks due to its impact on resources management. In fact, community members in Kamonyi district are aware on the limits of natural resources, especially lands. When the population is growing, without augmentation of these resources, there is an increase of disasters risks which results from the use of these resources. "This whole land was cultivated by my father-in-laws. He shared it with his 4 sons, included my husband. Now, this part in which we are, I have already shared with 3 sons of my husband. This remaining part will be also shared into 4 parts, because we have 4 children. Can you imagine! Life is difficult so that I regret why I have had all these children". This is a declaration of an old woman, explaining the relationship between population growth and disasters. She added due to the overuse of their land, the soil became degraded, and then, the famine is chronic in their family.

According to research findings, respondents working in mining activities have expressed the high level of awareness of the contribution of their activities on environmental degradation. The group of farmers has a big number of those who do not recognize their contribution on environmental degradation. Through focus group discussions, respondents have deeply explained that they, on the same time contribute on environmental degradation and its protection.

Regarding attitudes towards laws and policies protecting environment, the appreciation or negative attitudes are related to the impact of this law or policy on the respondent. It is in such way that some laws and policy like land law and law governing the urban Planning and building in Rwanda are the most known and appreciated by participants. Other laws and policies like biodiversity law and mine and geology policy are known and then appreciated by a few number of respondents. 


\subsection{Practices of Community Members Contributing to the Environmental Protection or Degradation and therefore to the Increase or Decrease of Disasters Risks}

\subsubsection{The Source of Energy used by Respondents}

Findings of research have shown that the most used source of energy is firewood, followed by petroleum and electricity. Solar power and biogas are used by a small number of research participants. Even if all energy sources have some impact on the environment, renewable energy provides substantial benefits for the climate, health, and economy. Therefore, efforts are needed to improve the use of renewable energy among community members in Kamonyi district.

\subsubsection{Farming Techniques}

Findings of research have revealed that 184 farmers use crop rotation, 62 have terraces, 127 use drainage and/or irrigation techniques, 118 use artificial fertilizers, while 135 use pesticides.

\subsection{There are Key Environmental Issues which are Associated with the Agricultural Sector}

\subsubsection{High Population Density on the Limited Land Resource}

the main issues putting pressure on agricultural productivity include high population density on the limited land resource. This has led to land fragmentation and reduction of farm sizes, continued intensive cultivation of land with no fallow and soil erosion, over cultivation without restoration of soil nutrients, weak extension and research services and increased vulnerability to climatic shocks like drought or heavy rains. In the context of Kamonyi community members, all farmers have confirmed that they use crop rotation technique. However, due to the high density of population, soils are overused. That were confirmed during Focus group discussions.

\subsubsection{Soil Erosion}

Agriculture practiced on the slopes of hills and mountains, coupled with deforestation has caused extensive land degradation and soil erosion. According to REMA (2014), About 40 per cent of Rwanda's land is classified by the FAO as having a very high erosion risk with about 37 per cent requiring soil retention measures before cultivation. Only 23.4 per cent of the country's lands are not prone to erosion (ROR, 2008). In Kamonyi district, soil erosion is remaining environmental problem.

\subsubsection{Climate Change}

Climate change and agriculture are interrelated processes, both of which take place on a worldwide scale. Global warming is projected to have significant impacts on conditions affecting agriculture, including temperature, precipitation and glacial run-off. These conditions determine the carrying capacity of the biosphere to produce enough food for the human population and domesticated animals. Rising carbon dioxide levels would also have effects, both detrimental and beneficial, on crop yields. Assessment of the effects of global climate changes on agriculture might help to properly anticipate and adapt farming to maximize agricultural production. Although the net impact of climate change on agricultural production is uncertain it is likely that it will shift the suitable growing zones for individual crops. Adjustment to this geographical shift will involve considerable economic costs and social impacts. At the same time, agriculture has been shown to produce significant effects on climate change, primarily through the production and release of greenhouse gases such as carbon dioxide, methane, and nitrous oxide. In addition, agriculture that practices tillage, fertilization, and pesticide application also releases ammonia, nitrate, phosphorus, and many other pesticides that effect the air, water, and soil quality, as well as biodiversity (Van der Warf, Hayo; Petit, Jean, 2002). In Kamonyi district, there is no doubt that agricultural techniques have an impact on climate change and vice versa.

\subsubsection{Drainage and Irrigation}

Irrigation can lead to a number of problems. Among some of these problems is the depletion of underground aquifers through overdrafting. Soil can be over-irrigated because of poor distribution uniformity or management wastes water, chemicals, and may lead to water pollution. Over-irrigation can cause deep drainage from rising water tables that can lead to problems of irrigation salinity requiring water table control by some form of subsurface land drainage. However, if the soil is under irrigated, it gives poor soil salinity control which leads to increased soil salinity with consequent 
buildup of toxic salts on soil surface in areas with high evaporation. This requires either leaching to remove these salts and a method of drainage to carry the salts away. Irrigation with saline or highsodium water may damage soil structure owing to the formation of alkaline soil (ILRI, 1989). During this research, 127 out of 184 farmers have mentioned that they use drainage and/or irrigation techniques.

\subsubsection{Environmental Impact of Pesticides and Environmental Effects of Fertilizers}

Synthetic pesticides are the most widespread method of controlling pests in agriculture. Pesticides can leach through the soil and enter the groundwater, as well as linger in food products and result in death in humans. Pesticides can also kill non-target plants, birds, fish and other wildlife. A wide range of agricultural chemicals are used and some become pollutants through use, misuse, or ignorance. Pollutants from agriculture have a huge effect on water quality. Agricultural nonpoint source (NPS) solution impacts lakes, rivers, wetlands, estuaries, and groundwater. Agricultural NPS can be caused by poorly managed animal feeding operations, overgrazing, plowing, fertilizer, and improper, excessive, or badly timed use of Pesticides. Pollutants from farming include sediments, nutrients, pathogens, pesticides, metals, and salts (United States Environmental Protection Agency, 2011). The use of fertilizers and agricultural chemicals pollute water; and agricultural activities and general mismanagement of the wetlands, further degrade and destroy them. During this research, 118 farmers revealed that they use artificial fertilizers, while 135 use pesticides.

\subsection{Land Use}

The Rwanda national land policy has been established in order to guide the following land reforms

- Strong pressure on the already spatially limited land resources by a rapidly growing population

- Domination of the agricultural sector which lacks any specialization in terms of human resources and equipment, and lack of alternative concrete and realistic options that would reduce the pressure on land resource;

- A land tenure system dominated by customary law which favors land fragmentation, a practice which reduces further the size of the family farms which are already below the threshold of the average surface area that is economically viable;

- A considerable number of landless persons who have to be resettled at all costs;

- Scattered farming plots that are difficult to manage due to the scattered mode of human settlement;

- Lack of a reliable land registration system that would guarantee the security of land tenure;

- Weak and inadequate existing methods of land-use planning and land improvement (outline of land potential, land use and land development; reliable methods of soil and water conservation);

- Disorderly and fraudulent land transactions, necessitating the establishment of regulations that would enable the authorities to give to the land a recognised market value which brings considerable profit to the Government Treasury;

- Unplanned use of marshlands which, in spite of their good agricultural soil, cannot be wholly recovered for agricultural purposes, in view of the following factors:

- Abundance of water which is necessary as a useful water reservoir;

- The soil make-up, which does not lend itself easily to the current cultivation methods;

- The biotic environment and biodiversity which should be protected at all costs;

- The obvious poor coordination among various institutions which use with land to support their activities (MINIRENA, 2004).

Findings of this research have shown that $37 \%$ of respondents respect guidelines of national land policy in the use and management of their lands. $9 \%$ of respondents accepted that they don't respect 
these guidelines, while $37 \%$ are not sure if they respect or not these guidelines. The question was not applicable for $37 \%$ of respondents. These include all respondents without land property.

\subsection{Forestry and Deforestation}

Deforestation causes the loss of habitat for millions of species, and is also a driver of climate change. Trees act as a carbon sink, in which they absorb carbon dioxide, an unwanted greenhouse gas, out of the atmosphere. By removing trees, the carbon dioxide is released into the atmosphere, and there is now less trees to absorb the increasing amount of carbon dioxide in the air. In this way, deforestation exacerbates climate change. When trees are removed from forests, the soils tend to dry out because there is no longer shade, and there are not enough trees to assist in the water cycle by returning water vapor back to the environment. With no trees, landscapes that were once trees can potentially become barren deserts. The removal of trees also causes extreme fluctuations in temperature (National Geograhic, 2015).

During this research, respondents were asked if they have participated in any activities related to forests conservation during these 2years. 13 of them have confirmed that they have planted forests, 74 have planted agroforestry trees, and 36 have planted trees in urban areas and on roadsides. 6 of them have harvested their forests with license, while harvested without license. 45 respondents have participated in trade of forest products.

\subsection{Mining and Building Activities}

Mining activities are said to be the source of the current state of the muddy River Nyabarongo waters. According to the interview with leaders in Kamonyi district, mining activities are "over controlled" in order to avoid their impact on the environment. Nobody can execute these activities without authorization from competent authorities. Following the interview with KAYENZI MINING COMPANY (KAMICO) LTD members, there is a regular control of the impact of their activities on the environment. However, this impact cannot be reduced definitively, as they confirm themselves. Disasters related to water pollution, deforestation and accidents are the main identified by community members in Kayenzi sector, as associated to mining activities.

For building activities, 24 out of 32 respondents have shown that they have respected the master plan for land management and urban planning. However, only $6 \%$ had the building permit. The interview with key informants revealed that administrative procedures before construction activities are not respected in rural areas, as in urban area. In addition, farmers don't want to go far from their lands, reason why sometimes, Master plans for land management are not respected.

\section{CONCLUSION AND RECOMMENDATIONS}

\subsection{Conclusion}

The objective of this research was to assess knowledge, attitudes and practices of local communities in Kamonyi district towards environmental protection as a disasters' risks reduction strategy.

Findings of the research revealed that $76 \%$ of respondents are aware of environmental degradation problem. $62 \%$ of respondents have confirmed that there is a direct relationship between environmental degradation and disasters. Human epidemics are the first category of disasters experienced in areas of respondents, as confirmed by $96 \%$ of them.

Regarding attitudes of community members in Kamonyi district, findings of this research revealed that the most appreciated technique as contributing on prevention of disasters is the prevention of erosion. 240 out of 384 respondents strongly agree with its effectiveness. The population growth is considered as a factor contributing on the increase of disasters risks due to its impact on resources management. In fact, community members in Kamonyi district are aware of the limits of natural resources, especially lands. When the population is growing, without augmentation of these resources, there is an increase of disasters' risks which results from the use of these resources.

About the Practices of community members contributing to the environmental protection or degradation and therefore to the increase or decrease of disasters risks, findings of this research have shown that the most used source of energy is firewood, followed by petroleum and electricity. Solar power and biogas are used by a small number of research participants. Even if all energy sources have 
some impact on the environment, renewable energy provides substantial benefits for the climate, health, and economy. Findings of the research have also revealed that 184 farmers use crop rotation, 62 have terraces, 127 use drainage and/or irrigation techniques, 118 use artificial fertilizers, while 135 use pesticides. Soil erosion, climate change, drainage and irrigation, over cultivation and environmental impact of pesticides and environmental effects of fertilizers, are key environmental issues which are associated with the agricultural sector in Kamonyi district. Guidelines of national land policy in the use and management of their lands are respected by $37 \%$ of respondents. $9 \%$ of research participants accepted that they don't respect these guidelines, while $37 \%$ are not sure if they respect or not these guidelines. The question was not applicable for $37 \%$ of respondents. For the issue of forestry and deforestation, 13 respondents have confirmed that they have planted forests, 74 have planted agroforestry trees, and 36 have planted trees in urban areas and on roadsides. 6 of them have harvested their forests with license, while harvested without license. 45 respondents have participated in trade of forest products. In Kamonyi district, mining activities are "over controlled" in order to avoid their impact on the environment. Nobody can execute these activities without authorization from competent authorities. Despite regular control of the impact of mining activities on the environment, it cannot be eliminated definitively, as confirmed by research participants. Disasters related to water pollution, deforestation and accidents are the main identified by community members in Kayenzi sector, as associated to mining activities.

The interview with key informants revealed that administrative procedures before construction activities are not respected in rural areas, as in urban areas. In addition, farmers don't want to go far from their lands, reason why sometimes, Master plans for land management are not respected.

Though there is no way of neutralizing all of the negative impacts resulting from disasters, efforts can be made in order to reduce their consequences. Knowledge on disaster management strategies, together with good practices and lessons learned can undoubtedly support this effort through wellinformed mitigative measures and preparedness planning (Centre for Disaster Resilience, 2014).

According to Moe et al. (2007) it is essential for practitioners in the disaster management field to be innovative and learn from lessons in order to adopt best practices throughout the disaster management cycle. Practitioners in disaster management should improve their skills and increase their level of knowledge, which requires investments in systems, databases and network structures so as to build a culture of learning from previous lessons and the adoption of best practices (Moe et al., 2007).

The objectives of this research have been achieved. However, other efforts are needed for improvement of knowledge of community members, in order to reduce their vulnerability to disasters. In addition, behavior change programs are much needed in this area so that sustainable development goals may be achieved.

\subsection{Recommendations}

- Considering the damaging effect of disasters on individuals, communities and nations, disasters' risk reduction need to be mainstreamed into development policies, plans and programs.

- To make disaster risk reduction sustainable for communities located in environmental hazard zones, a large number of diverse actors must be involved in the process and committed to follow up on any further actions.

- Involvements from the most vulnerable groups, like women and children are considered vital for successful and sustainable long-term achievements.

- Efforts are needed to improve practices of community members contributing to the environmental protection and therefore to the decrease of disasters' risks.

\section{ACKNOWLEDGMENT}

Results of this research are the outcome of the efforts provided by different persons. Our gratitude is addressed to anyone who, near or far, has contributed to the accomplishment of this work. We highly thank all participants in the research who gave information from which conclusions are drawn. Their collaboration is considered as the pillar of this work. 


\section{REFERENCES}

[1] Ben Wisner and Peter Walker. (2009). "Katrina and Goliath," Humanitarian Practice Network. Denver: Westview Press.

[2] FAO. (2015). The impact of natural hazards and disasters on agriculture and food security and nutrition.

[3] ILRI. (1989). Effectiveness and Social/Environmental Impacts of Irrigation Projects: a Review. In: Annual Report 1988. Wageningen

[4] ISDR. (2004). Environmental protection and disasters risk reduction.A community Leader's guide. Cape Town: Umvoto Africa Ltd.

[5] MIDMAR. (2012). The National Disaster Management Policy. Kigali.

[6] Mondal, P. (2015). Meaning, Definition and components of environment. Retrieved from http://www.yourarticlelibrary.com: http://www.yourarticlelibrary.com

[7] National Estuarine Research Reserve System. (2015). Agricultural Land Use Issues.

[8] National Geograhic (2015). Deforestation Retrieved from http://environment. National geographic. com/environment/global-warming/deforestationoverview/:http://environment.nationalgeographic. com/ environment/global warming/ deforestation-overview/

[9] United States Environmental Protection Agency. (2011). Risks of Pesticides use.

[10] Van der Warf, Hayo; Petit, Jean. (2002). Agriculture, Ecosystems and Environment.

[11] William Donner and Havidán Rodríguez. (2008). Disaster Risk and Vulnerability: The Role and Impact of Population and Society. Pennsylvania: Indiana University.

[12] Withgott, J. \& Brennan, S. (2009). Essential environment, third edition. San Francisco: Pearson Education.

[13] World Bank. (2002). Indicators of environment and sustainable development.Washington, DC.

[14] World Meteorological Organization. (2003). Climate Into the 21st Century. Cambridge: University Press.

Citation: Narcisse NTAWIGENERA, Dr. Callixte YADUFASHIJE, "Environmental Protection as Disasters" Risk Reduction Strategy in Rwanda: Knowledge, Attitudes and Practices of Community Members in Kamonyi District", International Journal of Research in Environmental Science (IJRES), vol. 5, no. 3, pp. 1-9, 2019. Available: DOI: http://dx.doi.org/10.20431/2454-9444.0503001

Copyright: (C) 2019 Authors. This is an open-access article distributed under the terms of the Creative Commons Attribution License, which permits unrestricted use, distribution, and reproduction in any medium, provided the original author and source are credited. 